\title{
MICROWAVE IRRADIATION EFFECT ON POLYPHENOL CONTENT AND ANTIOXIDANT ACTIVITY OF BASIL
}

\author{
ILDIKO LUNG ${ }^{\mathrm{a}}$, MARIA-LOREDANA SORAN ${ }^{\mathrm{a}}$, OCSANA OPRIŞ ${ }^{\mathrm{a}}$, \\ MANUELA STAN ${ }^{\mathrm{a}}$, CONSTANTIN BELE ${ }^{\mathrm{b}}$
}

\begin{abstract}
This study investigates the influence of microwave field derived from wireless router and mobile telephony sources on polyphenol content and antioxidant activity of basil. The total phenolic content of basil extracts was determined by Folin-Ciocalteu method. The amount of polyphenolic compounds in basil plants exposed to microwave irradiation was higher compared to control plants. Extracts of irradiated basil exhibit higher antioxidant activity than extracts of control plants, as evidenced by the three methods of determination used: 2,2-diphenylpicrylhydrazyl radical scavenging activity, oxygen radical absorbance capacity and Trolox equivalent antioxidant capacity assays. It was determined that microwave irradiation increased both antioxidant activity and polyphenol content of basil extracts. In addition, hydroalcoholic extracts obtained from basil plants exposed to GSM microwaves showed higher antioxidant activity than hydroalcoholic extracts of plants exposed to WLAN microwaves.
\end{abstract}

Keywords: polyphenols, basil, microwave influence, antioxidant activity

\section{INTRODUCTION}

The consumption of the phytochemical products/food supplements, in special phenolic compounds is correlated with a series of beneficial effects in the body, such as reducing the risk of diabetes, obesity, coronary artery disease, cancer of the colon and gastrointestinal dysfunctions [1]. Because in plants phenolic compounds are found under different forms the extraction from plant material raises special problems [2, 3]. Currently the existing analyzes

\footnotetext{
a National Institute for Research and Development of Isotopic and Molecular Technologies, 67103 Donat str., RO-400293, Cluj-Napoca, Romania.

b University of Agricultural Sciences and Veterinary Medicine, 3-5 Calea Manastur, RO-400372, Cluj-Napoca, Romania.

*Corresponding author loredana.soran@itim-cj.ro
} 
protocols appeals to classical techniques of liquid - solid extraction. Among these, the most commonly used are maceration, refluxing and Soxhlet extraction. Due to disadvantages that show they tend to be replaced by techniques with lower reagent consumption, lower energy and time, having however similar efficiency. For this purpose, have been implemented techniques such as ultrasound-assisted solvent extraction [4-6], microwave assisted solvent extraction [7], accelerated solvent extraction/pressurized liquid extraction carried out in dynamic and static mode [8] etc. Usually, for extraction of polyphenolic compounds must be performed an optimization [9] regarding the extraction system [10] solvent and plant material ratio, the effective time and extraction conditions, and each technique presenting specific parameters.

The obtained polyphenolic extract can be analyzed both globally nonspecific, determining the total polyphenols and specific. In order to determine the total polyphenols, it is used spectrophotometric method, using specific reagents. There are two such reagents: Folin-Ciocalteu reagent and Arnow's reagent [11-13]. The specific determination can be achieved through chromatographic methods, most used being high-performance liquid chromatography with diode array detector [10] or coupled with a mass spectrometer [14].

Basil is an important medicinal plant and a culinary herb from the Lamiaceae family, known for carminative, galactogogue, stomachic and antispasmodic properties used in folk medicine. It is also known for its antiinflammatory, antiviral and antimicrobial activities [15].

Under various biotic and abiotic stresses, plants can respond to produce secondary metabolites such as phenolic compounds, terpenoids, and alkanoids [16, 17].

Currently, due to the technological development, there is an exponential growth in the use of mobile phones and wireless devices, thus leading to an increase of electromagnetic radiation level and the emergence of a new type of stress, the electromagnetic field, especially in the microwave range $(1-100 \mathrm{GHz})[18,19]$. Numerous studies confirm that microwave radiation influences the living organisms, including plants, even at irradiation power under limits [20-22].

This manuscript reports the effect of the microwave field on polyphenolic content and antioxidant activity of basil. New results obtained by this work complete the study presented in our previous paper [23]. The basil was grown now in GSM and WLAN field. In this study, the grinding followed by centrifugation was used as extraction method instead of microwave assisted extraction. The antioxidant activity was determined and correlated with total polyphenol content. 


\section{RESULTS AND DISCUSSION}

The basil seedlings were exposed to microwave radiation of GSM and WLAN frequency bands. The effect on total phenolic content and antioxidant activity was studied for irradiated and control (non-irradiated) plant samples.

\section{Determination of Total Phenolic Content}

In this work, the total polyphenol content of basil plants grown in the presence of microwave field and in normal conditions was analysed by the conventional spectrophotometric Folin-Ciocalteu method (Figure 1).

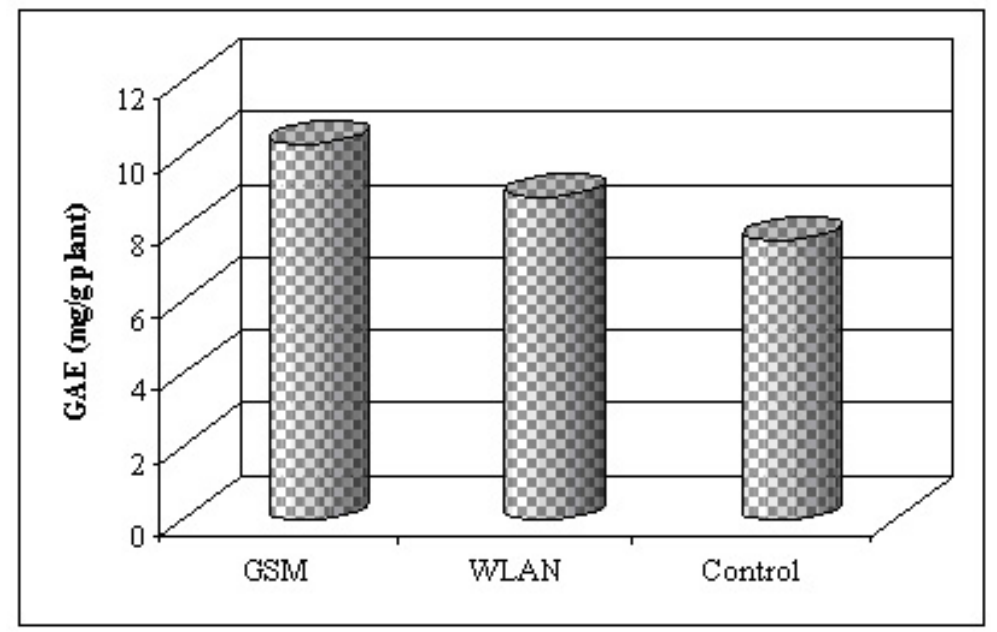

Figure 1. Total polyphenol content expressed as gallic acid equivalents in basil.

The amount of polyphenolic compounds was expressed as mg gallic acid/g fresh weight (FW), using the linear equation of the standard calibration curve: $y=0.6687 x+0.007\left(R^{2}=0.9987\right)$. It was observed that in the case of microwave irradiated plants the polyphenolic amount was higher compared to the control plants. The highest polyphenol quantity was determined in basil irradiated with GSM frequency microwaves (10.23 mg GAE/g plant).

\section{Total antioxidant activity}

Three antioxidant activity methods have been used to compare the antioxidant activity of irradiated and reference basil plants. DPPH method is often used due to stability, simplicity and its reproducibility [24]. 
The ORAC method is based on the use of fluorescein with progress of the reaction by decreasing of fluorescence emission. The decrease of fluorescence in the presence of radical species, including the peroxyl species generated by AAPH is an index of antioxidant capacity against free radical species [25].

ABTS assay is considered as a method that measures the redox ability of the antioxidant mixture in relation to the radical cation ABTS+. This method is based on the absorption of plant extracts at $734 \mathrm{~nm}$ [26].

The antioxidant activity determined by DPPH, ORAC and TEAC methods (Figure 2) was expressed in mM Trolox equivalents ( $\mathrm{mM}$ Trolox/g sample), using the linear equation of the standard calibration curve: $y=0.0008 x$ $+0.0025\left(R^{2}=0.9994\right)$ for DPPH method, $y=0.153 x+0.3451\left(R^{2}=0.9902\right)$ for ORAC method and $y=0.0008 x+0.0028\left(R^{2}=0.997\right)$ for TEAC method.

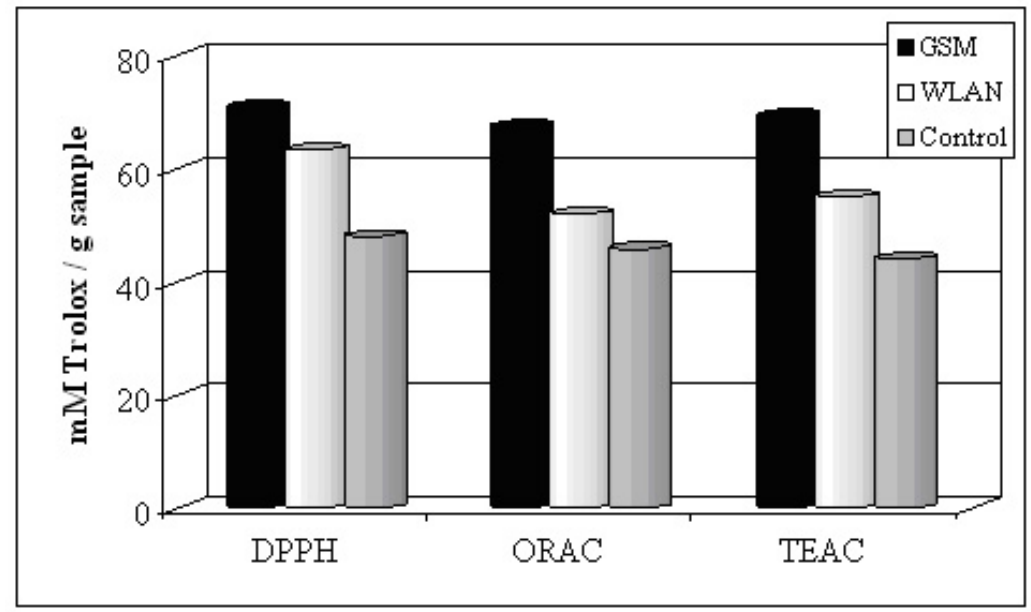

Figure 2. The antioxidant activity of basil extracts.

Plants irradiated with microwaves have shown highest antioxidant activity, evidenced by the three methods of determination: DPPH, TEAC and ORAC. In addition, the extracts from basil plants exposed to GSM microwaves have shown highest antioxidant activity than those of the plants exposed to WLAN microwaves. The values of antioxidant activity determined by the three analysis methods were very close to each other.

The increased antioxidant activity of the extracts obtained from irradiated plants can be correlated with the increase in the amount of polyphenols. 
MICROWAVE IRRADIATION EFFECT ON POLYPHENOL CONTENT AND ANTIOXIDANT ACTIVITY...

\section{CONCLUSIONS}

The objective of the present study was to investigate the effect of lowintensity microwave radiation on the total amount of polyphenols and antioxidant activity of basil. As result of our studies, microwave irradiation increased both antioxidant properties and polyphenol content of basil. Thus, the amount of total polyphenols in microwave irradiated plants increase with $33.73 \%$ (GSM) and 15.16\% (WLAN) compared to control plants, respectively. In addition, the antioxidant activity was higher for the extracts obtained from GSM irradiated plants compared to WLAN.

\section{EXPERIMENTAL SECTION}

\section{Plant material}

The plant material used for the current experiment was basil, which was primarily grown from seeds (ARO, Romania). Three weeks after sowing, the plants were placed in identical anechoic chambers [27]. Test (irradiated) and control plants were subjected to the same environment (humidity and temperature). Stimulation was performed with microwaves modulated by a specific generator in GSM frequency domain (860 - $910 \mathrm{MHz}$ range) and WLAN communications protocol, in the $2.412-2.48 \mathrm{GHz}$ frequency band. The irradiation was performed over two weeks, afterwards the plants were taken from the chambers and the vegetal material was extracted.

\section{Chemical reagents}

2,2'- Diphenyl - picrylhydrazyl (DPPH), 6 - hydroxy-2,5,7,8tetramethylchroman -2 carboxylic acid (Trolox), fluorescein sodium salt, 2,2azobis (2-amidinopropane) dihydrochloride (AAPH), 2,2'-azinobis(3ethylbenzthiazoline-6-sulfonic acid) (ABTS), potassium persulfate, FolinCiocalteu reagent, gallic acid and anhydrous carbonate were employed from Sigma-Aldrich, Germany, while ethanol was purchased from Chimopar, Romania. All chemicals were of analytical grade.

\section{Preparation of plant extracts}

One gram of fresh leaves was mortared with $1 \mathrm{~g}$ quartz sand after which $25 \mathrm{~mL}$ of $80 \%$ ethanol was added. The mixture was stirred for $1 \mathrm{~h}$ at $4^{\circ} \mathrm{C}$ and then centrifuged at $10.000 \mathrm{rpm}$ for 15 minutes. The supernatant was removed and the pellet was resumed with $5 \mathrm{~mL} \mathrm{80 \%} \mathrm{ethanol,} \mathrm{stirred} \mathrm{for} 15$ minutes and centrifuged following the same procedure. Supernatants have been finally combined. Each sample was extracted independently in triplicate and the analyses were performed in the same day. Each extract was performed in three parallel samples. 


\section{Determination of Total Phenolic Content}

The total polyphenol content was spectrophotometrically determined, using gallic acid as standard, according to the Folin-Ciocalteu method [28]. In a $10 \mathrm{~mL}$ volumetric flask to $1 \mathrm{~mL}$ of extract was added $5 \mathrm{~mL}$ of distilled water and $0.5 \mathrm{~mL}$ Folin-Ciocalteu reagent. After $3 \mathrm{~min}, 1.5 \mathrm{~mL}$ of sodium carbonate $(5 \mathrm{~g} / \mathrm{L})$ was added and filled up to $10 \mathrm{~mL}$ with distilled water. Then, the samples were kept in a water bath at $50^{\circ} \mathrm{C}$ for $16 \mathrm{~min}$. After cooling, their absorbances were read at $765 \mathrm{~nm}$ against distilled water as the blank, using a Shimadzu UV-160A spectrophotometer (Kyoto, Japan) with $1 \mathrm{~cm}$ optical path length quartz cuvette. All measurements were taken in triplicates and mean values were calculated.

The concentration of polyphenols in samples was derived from a standard curve of gallic acid ranging from 10 to $50 \mu \mathrm{g} / \mathrm{mL}$ (R2=0.9996).

\section{Evaluation of total antioxidant activity}

Antioxidant activity was investigated by three different in vitro antioxidant methods: 2, 2-diphenylpicrylhydrazyl radical scavenging activity (DPPH), oxygen radical absorbance capacity (ORAC) and Trolox equivalent antioxidant capacity (TEAC) assays.

\section{DPPH assay}

DPPH $(80 \mu \mathrm{M})$ was dissolved in absolute ethanol (98\%). The mixture was vigorously stirred and allowed to perfecting for 10 minutes at room temperature. 96 well plates were filled with $40 \mu \mathrm{L}$ samples and $250 \mu \mathrm{L}$ radical solutions $[29,30]$. The decrease of absorption for resulting solutions was monitored at $515 \mathrm{~nm}$ for 30 minutes. The results were expressed as $\mathrm{mM}$ Trolox I g plant.

\section{ORAC assay}

AAPH $(0.414 \mathrm{~g})$ was dissolved in $10 \mathrm{~mL}$ of $75 \mathrm{mM}$ phosphates buffer (pH 7.4) to obtain a final concentration of $153 \mathrm{mM}$ [31]. A stock solution of fluorescein $(4 \times 10-3 \mathrm{M})$ was prepared in $75 \mathrm{mM}$ phosphates buffer solution $(\mathrm{pH}=7.4)$. For experimental measurements the exterior well plates were not used. These well plates were filled with $300 \mu \mathrm{L}$ of water, while the interior well plates were used for the experimental measurements. Thus, were added $150 \mu \mathrm{L}$ of the working solution of fluorescein sodium salt in each of the interior well plates. In the control well plates have been added $25 \mu \mathrm{L}$ of phosphates buffer $75 \mathrm{mM}$. In the well plates for the standards were introduced $25 \mu \mathrm{L}$ diluted Trolox and in the sample well plates $25 \mu \mathrm{L}$ alcoholic extract of the analyzed samples. The samples were incubated for $30 \mathrm{~min}$. for equilibration in the Synergy HT Multi-Detection Microplate TM reader device (Bioteck Instruments, Winooski, VT) at $37^{\circ} \mathrm{C}$. Reactions were initiated by adding $25 \mu \mathrm{L}$ AAPH solution. The fluorescence was measured by kinetic monitorization with data taken at each minute at $485 \mathrm{~nm}$ excitation filter, 20 $\mathrm{nm}$ bandpass, emission filters at $585 \mathrm{~nm}, 20 \mathrm{~nm}$ bandpass. 
MICROWAVE IRRADIATION EFFECT ON POLYPHENOL CONTENT AND ANTIOXIDANT ACTIVITY...

\section{TEAC assay}

ABTS stock solution was obtained by the reaction of $7 \mathrm{mM} / \mathrm{L}$ aqueous solution and $2.45 \mathrm{mM} / \mathrm{L}$ potassium persulfate and a completion in the dark at room temperature for 12-16 $\mathrm{h}$ before use. The working solution of ABTS was obtained by ethanol dilution of the stock solution at absorption of $0.70 \pm 0.02$ $\mathrm{AU}$ at $734 \mathrm{~nm}$, verified by Biotek Synergy HT spectrophotometer, USA. $17 \mu \mathrm{L}$ of sample was added to $170 \mu \mathrm{L}$ ABTS solution. The results were expressed as $\mathrm{mM}$ Trolox/g plant [25].

\section{ACKNOWLEDGMENTS}

Financial assistance provided through the Ministry of Education and Research of Romania (PN II Research Program, project 51-098 / 2007 and Human Resources program: project TE 76 / 2011) is gratefully acknowledged.

\section{REFERENCES}

1. K.A. Ross, T. Beta, S.D. Arntfield, Food Chemistry, 2009, 113, 336.

2. S. Nyiredy, Journal of Chromatography B, 2004, 812, 35.

3. P. Mattila, J.J. Kumpulainen, Journal of Agricultural and Food Chemistry, 2002, $50,3660$.

4. M. Kivilompolo, T. Hyotylainen, Journal of Chromatography A, 2009, 1216, 892.

5. R. Japon-Lujan, J.M. Luque-Rodriguez, M.D. Luque de Castro, Journal of Chromatography A, 2006, 1108, 76.

6. R.M. Alonso-Salces, A. Barranco, E. Corta, L.A. Berrueta, B. Gallo, F. Vicente, Talanta, 2005, 65, 654.

7. T.S. Ballard, P. Mallikarjunan, K. Zhou, S. O'Keefe, Food Chemistry, 2010, 120, 1185.

8. X. Jun, S. Deji, Z. Shou, L. Bingbing, L. Ye, Z. Rui, International Journal of Pharmaceutics, 2009, 382, 139.

9. E.M. Silva, H. Rogez, Y. Larondelle, Separation and Purification Technology, 2007, 55, 381.

10. G.A. Akowuah, Z. Ismail, I. Norhayati, A. Sadikun, Food Chemistry, 2005, 93, 311.

11. S. Albu, E. Joyce, L. Paniwnyk, J.P. Lorimer, T.J. Mason, Ultrasonics Sonochemistry, 2004, 11, 261.

12. R.J. Grubesic, J. Vukovic, D. Kremer, S. Vladimir-Knezevic, Journal of Pharmaceutical and Biomedical Analysis, 2005, 39, 837. 
13. O. Yesil-Celiktas, P. Nartop, A. Gurel, E. Bedir, F. Vardar-Sukan, Journal of Plant Physiology, 2007, 164, 1536.

14. A. Figueirinha, A. Paranhos, J.J. Perez-Alonso, C. Santos-Buelga, M.T. Batista Food Chemistry, 2008, 110, 718.

15. M.T. Baratta, H.J.D. Dorman, S.G. Deans, A.C. Figueiredo, J.G. Barroso, G. Ruberto, Flavour and Fragrance Journal, 1998, 13, 234.

16. R.N. Bennett, R.M. Wallsgrove, New Phytologist, 1994, 127, 617.

17. D.K. Kliebenstein, Plant Cell \& Environment, 2004, 27, 675.

18. A. Vashisth, S. Nagarajan, Bioelectromagnetics, 2008, 29, 571.

19. D. Roux, A. Vian, S. Girard, P. Bonnet, F. Paladian, E. Davies, G. Ledoigt Planta, 2008, 227, 883.

20. A. Vian, D. Roux, S. Girard, P. Bonnet, F. Paladian, E. Davies, G..Ledoigt, Plant Signaling \& Behavior, 2006, 1, 67.

21. W. Stankiewicz, M.P. Dabrowski, R. Kubacki, E. Sobiczewska, S. Szmigielski Electromagnetic Biology and Medicine, 2006, 25, 45.

22. I. Lung, M.L. Soran, C. Tudoran, C. Marutoiu, Central European Journal of Chemistry, 2013, 11, 535.

23. I. Lung, M.L. Soran, M. Stan, D. Podar, Advances in Research, 2013, 1, 1-10.

24. T. Katsube, H. Tabata, Y. Ohta, Y. Yamasaki, E. Anuurad, K. Shiwaku, Y. Yamane, Journal of Agricultural and Food Chemistry, 2004, 52, 2391.

25. N. Pellegrini, M. Serafini, B. Colombi, D. Del Rio, S. Salvatore, M. Bianchi, F. Brighenti, Journal of Nutrition, 2003, 133, 2812.

26. H.B. Li, C.C. Wong, K.W. Cheng, F. Chen, LWT - Food Science and Technology, 2008, 41, 385.

27. E. Surducan, V. Surducan, A. Halmagyi, "Process and installation for stimulating plant development in microwaves field" Romanian Patent. RO 125068B1/2012.

28. K. Slinkard, V.L. Singleton, American Journal of Enology and Viticulture, 1977, 28, 49.

29. W. Brand-Williams, M.E. Cuvelier, C. Berset, LWT - Food Science and Technology, 1995, 28, 25.

30. M.B. Arnao, A. Cano, J.F. Alcolea, M. Acosta, Phytochemical Analysis, 2001, 12, 138.

31. D. Huang, B. Ou, M. Hampsch-Woodill, J.A. Flanagan, R.L. Prior, Journal of Agricultural and Food Chemistry, 2002, 50, 4437. 